\title{
“LA CONDESA HA MUERTO". HERENCIAS PICTÓRICAS METAMORFOSEADAS EN L'APOLLONIDE (BERTRAND BONELLO, 2011)
}

\section{"THE COUNTESS IS DEAD". METAMORPHOSED PICTORIAL INHERITANCES IN L'APOLLONIDE (BERTRAND BONELLO, 2O11)}

\section{Resumen:}

Pretendemos rastrear la herencia pictórica que emerge en la puesta en escena de L'Apollonide. Casa de tolerancia (L'Apollonide. Souvenirs de la maison closee, Bertrand Bonello, 2011), cuyo sentido trasciende la mera ambientación de época. Toilettes postimpresionistas, orientalismos simbolistas y salidas al campo de aire impresionista forman parte de las referencias de las cuales el filme se nutre y que, a la vez, metamorfosea para escribir un relato detenido en el eterno final del siglo XIX, cuyo lacónico tedio y militante artificialidad no son obstáculo para la irrupción despiadada de la barbarie. Partiendo de la identificación de intertextualidades y el análisis textual de la materialidad fílmica, proponemos defender que L'Apollonide aprehende la estética y el sentir decadente del arte francés del crepúsculo decimonónico para construir un relato que humaniza con mirada contemporánea el día a día de las prostitutas que trabajan en un elitista burdel abocado al cierre. La configuración de la puesta en escena que reclama determinados referentes pictóricos es clave para repensar, redibujar y proponer un reverso al mito de la femme fatale pictórica.

\section{Teresa Sorolla Romero \\ Universitat Jaume I, España tsorolla@uji.es}

\section{Abstract:}

We intend to trace the pictorial heritage that emerges in the staging of L'Apollonide, Souvenirs of the maison closee (Bertrand Bonello, 2011), whose meaning transcends the mere ambience of the time. Postimpressionist toilettes, symbolist orientalisms and outings to impressionistic landscapes are part of the references of which the film is nourished and, at the same time, metamorphosizes in order to write a story detained in the eternal ending of the nineteenth century, whose laconic tedium and militant artificiality are no obstacle to the ruthless irruption of barbarism. Starting from the identification of intertextualities and the textual analysis of filmic materiality, we propose that L'Apollonide apprehends the aesthetic and the decadent feeling of French art in the twilight of the century to build a story that humanizes -through a contemporary look - the day-to-day life of the prostitutes who work in an elitist brothel about to shutting. The configuration of the mise-en-scène demands the identifiction of certain pictorial referents key in order to rethink, redraw and propose a reverse to the myth of the pictorial femme fatale.

Palabras clave: cine y pintura; L'Apollonide; cultura visual; intertextualidad; arte y cine

Keywords: Cinema and painting; L'Apollonide; Visual Culture; Intertextuality; Art and Cinema 
Cómo citar: Sorolla Romero, T. (2018). "La condesa ha muerto". Herencias pictóricas metamorfoseadas en L'Apollonide (Bertrand Bonello, 2011). Fotocinema. Revista científica de cine y fotografía, $\mathrm{n}^{0}$ 16, pp. 173-195. Disponible: http://www.revistas.uma.es/index.php/fotocinema/ DOI: http://dx.doi.org/10.24310/Fotocinema.2017.v0i16

\section{Introducción. El fin del fin de siglo}

En el salón de estar del elegante burdel parisino L'Apollonide, los clientes y las jóvenes que trabajan allí se dejan caer con indolencia en divanes y sillones mientras, haciendo gala de la decadencia que arrastra el agotamiento del siglo romántico por excelencia, se distraen bebiendo champán de un orinal dorado que se van pasando de unos a otros. La madame Marie-France (Noémie Lvovsky) lee en voz alta la carta de una adolescente que solicita entrar a trabajar en la maison closee y adjunta un esbozo de su rostro dibujado por ella misma. Uno de los clientes se pregunta, ante la llegada inminente de la nueva joven: “ahora que la condesa ha muerto, ¿quién será la belleza del siglo XX?”. Esta línea de guion a la que la enunciación del relato parece no conceder importancia - la cámara ni siquiera enfoca al hombre que la pronuncia sino que sigue el paseo de la prostituta Samira (Hafsia Herzi) — nos permite introducir diversas cuestiones que sirven para avanzar la posición discursiva y reflexión del filme sobre los estertores de la estética decimonónica imbricada con su particular modo de narrar.

La mujer aludida en la pregunta, a la que nadie vuelve a mencionar, es probablemente Virginia Oldoini, Condesa de Castiglione, pues fallece el mismo noviembre de 1899 en que se ubica la diégesis del filme y es una figura cuya decadente fama era bien conocida entre la alta sociedad francesa. La antaño exuberante condesa, amante durante un tiempo de Napoleón III $^{1}$, se dedicó

Este trabajo ha sido realizado con el apoyo del Proyecto de Investigación La crisis de lo real: la representación documental e informativa en el entorno de la crisis financiera global, financiado por la Universitat Jaume I, para el periodo 2015-2017, con código P1•1A2014-05, bajo la dirección del Dr. Javier Marzal Felici.

1 La condesa de Castiglione fue enviada a Francia en 1855 por Cavour, posteriormente Presidente del Consejo de Ministros de Italia y protagonista político de su unificación, con el 
durante décadas, desde $1856^{2}$, a encargar fotografías de sí misma en las que ella componía la puesta en escena. Su uso de la fotografía como embalsamadora del tiempo adquiere literalidad cuando "perdida por completo su situación privilegiada en torno a Napoleón III, [...] comenzó el plan de recrear los grandes momentos de su vida" (Segade, 2008, p. 280). Los cientos de negativos, en los que la condesa se hace retratar con la autoconsciencia de quien se quiere adorado por la admiración ajena, despliegan reconstrucciones como la de su primer encuentro con el emperador o el lucimiento de los más diversos disfraces (desde reina de corazones, maja, o aristócrata dieciochesca hasta carmelita). Si a la fotografía se le atribuye la condición de ser huella de una ausencia (Bazin, 1999) el archivo retratístico que La Castiglione mantuvo, de forma intermitente, hasta su vejez, es testigo melancólico de su resistencia al paso del tiempo. Registrando aquella lejanía que se sabe irrecuperable (Benjamin, 2004), atestigua su voluntad de detener la degradación que terminaría alcanzándola en sus fúnebres apartamentos parisinos, convertida por la opinión pública en "símbolo de la amoralidad del Segundo Imperio" (Segade, 2008, p. 284).

La mención velada a la que fuera, a su muerte, reverenciada como leyenda por el dandi Barón de Montesquiou, va acompañada en L'Apollonide del interrogante de qué belleza la sustituirá en el próximo cambio de siglo. La continuación de la escena resulta discretamente significativa. Samira, en respuesta al interrogante, susurra cariñosamente a su compañera Madeleine, apodada "la judía" (Alice Barnole), que ella será la próxima gran beldad. Por corte directo, la escena se traslada a la entrada del burdel, en la que un joven y un hombre maduro son recibidos por una mujer vestida de negro. El apuesto joven, cliente habitual de Madeleine que poco después sube a "la habitación de cortinas negras" con ella, tras atarla supuestamente como parte del juego sexual le corta brutalmente ambas comisuras de los labios, marcándola de por vida con una dolorosa sonrisa siniestra3 ${ }^{3}$ La continuidad de la autocomplaciente belleza

objetivo de obtener el apoyo del emperador Napoleón III en el conflicto entre el Piamonte y Austria.

2 Desde 1856, visitó el importante estudio fotográfico Mayer \& Pierson. A partir de 1861, fue el fotógrafo Pierre-Louis Pierson quien acudía invitado a su mansión para retratarla.

3 El motivo del rostro o sonrisa rasgada cobra protagonismo también en filmes como El hombre que ríe (Paul Leni, 1928), La dalia negra (Brian De Palma, 2006) o Sin perdón (Clint 
aristocrática queda, violenta y simbólicamente, seccionada sin previo aviso: del mismo modo que la mujer se fió de su habitual cliente, la enunciación se distrae acudiendo al salón común donde otros señores y chicas pasan despreocupadamente el tiempo e introduce de fondo una dulce canción al piano para cortar, directamente, a los gritos desgarrados de Madeleine y los espacios vacíos de la mansión donde éstos resuenan. Desde fuera de campo se anticipa el horror. Cuando la cámara vuelve a la alcoba, muestra a la mujer atada en cruz a la cama, bramando con el rostro ensangrentado ${ }^{4}$. La brutal crucifixión horizontal, el corte físico, marca el tránsito al siglo XX. En el siguiente plano, negro, fuden los rótulos "Marzo, 1900. En los albores del siglo XX".

Así pues, si Buñuel, en 1929, seccionaba un ojo para avisar de que iba a obligar al espectador a mirar de otro modo, Bonello utiliza lo hiriente del corte sobre la carne humana para destrozar la potencial belleza del siglo e inclinarla forzosamente hacia lo grotesco. La no linealidad y la fragmentación de un relato, a la postre, postmoderno, fractura la angustiosa escena de la tortura. El meganarrador (Gaudreault, 1988), desde su posición de "cuerpo simbólico del autor real en el campo textual, tramoyista invisible que mueve los hilos de la escena” (Gómez-Tarín \& Marzal, 2015, p. 28), juega constantemente con el hecho de que el espectador sabe desde el planteamiento qué ha sucedido en ese terrible encuentro para generar inquietud con diversos flashbacks que vuelven a él hasta que, finalmente, dedica un primer plano al rasgado de la mejilla de la joven. De este modo, el filme no solamente niega la hegemonía de lo bello. Anticipa también el horror sistemático que caracterizará al siglo XX —no en

Eastwood, 1992). En esta última, además, es también una prostituta decimonónica el objeto de repentinos cortes violentos por parte de un par de vaqueros, ultraje que motiva la búsqueda de venganza por parte del resto de prostitutas que ofrecen una recompensa económica a quien mate a los agresores. Los paralelismos del filme de Eastwood con el que nos ocupa son de corte más argumental que estético, pues bebe del imaginario visual del género western.

4 Pedro Ortega ha estudiado cómo el motivo visual de la mujer crucificada, que se extiende a lo profano en el siglo XIX se relaciona, en una de sus vertientes, con la convergencia entre castigo, tortura y excitación sexual propia de las "prácticas sadomasoquistas [...] cuyo pilar [...] no es sino el Marqués de Sade" (2015, p. 299). Sin embargo, ya el autor reconoce que más allá de la fantasía masculina del sometimiento de la mujer que subyace a la femme fatale "La mujer crucificada en el fin de siglo no es una iconografía únicamente misógina. [...] hay toda una serie de mujeres-Cristo que quedan fuera de la misoginia finisecular” $(2015$, p. 300) así como alegorías de naciones atacadas que toman la forma de la mujer en la cruz. Del mismo modo, en el golpe frío con el que Bonello introduce las consecuencias de la agresión física no hay lugar a erotización alguna. 
balde la mujer lleva el sobrenombre de "la judía" - y altera el reposo de la episódica y progresiva narrativa decimonónica.

De algún modo, el fin de una era y el inicio convulso de otra viene de la mano del giro estético hacia lo abyecto. Explica Carlos Losilla que "es una representación del fin: de una forma de vida, de una manera de filmar el pasado, de un cambio de siglo que también podría ser el nuestro. [...] El prostíbulo como antesala del Apocalipsis" (2012: 29). Y, tal y como iremos desarrollando, L’Apollonide respeta una cuidadosa escenografía historicista para adueñarse de los referentes pictóricos de la época que representa y ponerlos al servicio de relatar la historia de las prostitutas de la casa de tolerancia empatizando con ellas.

Con tal fin, nos proponemos atender en el siguiente apartado la cristalización del marco teórico en el filme, para rastrear en el siguiente bloque la presencia de la pintura en la puesta en escena, ya sea de forma literal - lienzos decimonónicos que pueblan las paredes del espacio representado- o indirecta - mediante referencias más sutiles construidas desde la composición de determinados encuadres-.

\section{Marco teórico. El refugio de la artificialidad ante la inminencia del fin}

L'Apollonide no se comprende sin tener presente, conjuntamente a la identificación de intertextualidades y el análisis cinematográfico, el contexto cultural al que alude, algunos de cuyos pilares básicos se presentifican en la narrativa del filme, además de empapar su visualidad.

En el contexto posterior a la desastrosa derrota en la guerra francoprusiana (1870-1871) y las duramente reprimidas revueltas de la Comuna de París, un pesimismo endémico impregna el arte finisecular francés ${ }^{5}$. Una abúlica "sensación de fracaso y de impotencia vitales [...] melancolía turbia, inactiva, complaciente, a un punto del placer, pero también del fatalismo” (De Villena,

5 Conviene matizar que nos referimos, especialmente, al arte de sensibilidad simbolista, más asociado al concepto de "fin de siglo", pues el optimismo del arte impresionista escaparía a esta observación. 
2001, p. 15-18), marca el decadentismo que se recrea en una agonía empalagosa, en un desfallecimiento mórbido, lujoso, libidinosamente macabro. Esa sensación del mal del siglo, del agotamiento de un tiempo enfermo, es catapultada por Baudelaire y abrazada por Verlaine, Rimbaud, Mallarmé o von Hofmannsthal. Paralelamente, se corporeiza en los lienzos de Moreau, FantinLatour, Lévy-Dhurmer, o, más allá de Francia, Burne-Jones, Klimt, Von Stuck, Redon, Rops o Beardsley.

La inmovilidad claustrofóbica y el tedio de una espera estéril se trasladan a L'Apollonide, por un lado, de la mano del vicio por la artificialidad como único encuentro posible con lo bello, representado por los caprichos sexuales de los clientes ociosos del burdel. La acción del filme se detiene en observar el lento transcurrir del fin de la casa, obligada a cerrar por una inasumible subida del alquiler. La cámara recorre lenta y paciente, desde el comienzo, los pasatiempos inocuos previos o posteriores al comercio sexual, que puede tener lugar o no. El encierro prácticamente perpetuo en la pesada arquitectura de la mansión contribuye a generar la sensación de asfixia y atemporalidad que no mengua pese a su decoración preciosista. Tal y como advierte Samira a la recién llegada Pauline (Iliana Zabeth), las chicas no pueden salir de allí si no van acompañadas de madame o de algún cliente de la casa. Eduard Fuchs explica:

Cuando en 1851 volvieron a permitirse los burdeles, cerrados durante algún tiempo, la policía exigió que se guardaran estas formas. Un escritor contemporáneo escribía: se obligó a ocultar al exterior la visión del vicio, es decir, su sede. Se fue incluso más lejos de lo necesario y se la envolvió de misterio. Los burdeles, elegantes por fuera, parecían hechizados; sus ventanas bajadas, la ausencia de personas a la vista, las misteriosas puertas de vaivén, todo era indicado para estimular la curiosidad o proporcionar al paseante una excusa adecuada para visitarlos. (Fuchs, 1996, p. 288)

A propósito de esta clausura, mencionábamos en otro lugar (García Catalán y Sorolla Romero, 2014) que el palacete, antesala de la muerte, cohesiona los retales de vidas que configuran el relato coral. Su horror vacui se erige en metáfora de la cárcel de apariencias destinada a desaparecer, en definitiva, por la inoperancia de su modo de vida a las puertas del nuevo siglo. De hecho, al margen de la salida al campo que mencionaremos más adelante, el único 
momento en que la enunciación nos permite salir de la mansión es cuando el farol rojo que la señala como burdel es apagado definitivamente. Tras ese instante, el tiempo del relato lleva a cabo una elipsis que salta hasta el mismo portal del París del siglo XXI para cerrar el filme con la actante que interpreta a Clotilde (Céline Sallette) bajando de un coche. El rol de prostituta es mantenido por la joven a lo largo del tiempo, connotando la permanencia del malestar independientemente del cambio de las condiciones concretas de la profesión y del paso de la Historia.

Factores como el desbordamiento de la prostitución en las ciudades industriales miserablemente superpobladas, la incorporación masiva de la mujer obrera al mundo laboral, el temor a las enfermedades venéreas y la creciente fuerza de los movimientos feministas son tenidos en cuenta por autores como Erika Bornay (1990), Pilar Pedraza (1991) o Bram Dikjstra (1994) para dar explicación a la misoginia finisecular que se ensaña con la figura de la mujer como culpable de todos los males del mundo, encarnada en las figuras de insidiosas Evas, Salomés, Judiths, Dalilas, Cleopatras, Pandoras, Medeas, esfinges, sirenas o, directamente, personificaciones de la sífilis y la muerte:

la familiaridad de casi todos los hombres de la época con este fenómeno, hizo que muchos, bajo la experta guía de los biosexistas, llegaran a la conclusión de que la culpa de todo se encontraba en las profundidades de la naturaleza femenina [...] Una confusa mezcla de deseo sexual y culpa, un vago sentimiento de diferencia de clase y explotación, y un anhelo de conservar los privilegios conseguidos hacían que las prostitutas les pareciesen a estos hombres [...] los instrumentos mediante los que el proletariado se vengaba de los ricos (Dijkstra, 1990).

Veremos más adelante que el juego establecido por Bonello con la estética de la femme fatale al viajar hasta el tiempo de su esplendor, lejos de trasladar el arquetipo, apunta hacia su carácter de preferencia masculina re-presentada. Las chicas de L'Apollonide, con el objetivo de conseguir clientes y saldar sus deudas con la madame, se atavían con largos collares que les salpican la piel, diademas doradas, generosos corsés o vaporosas enaguas que dejan entrever a los clientes la mercancía que tienen a su disposición. Sin embargo, rasgos como los ojos oscurecidos o los labios rojos son mostrados en tanto maquillaje artificial cuyo 
coste económico, además, les supone un lastre para lograr su independencia. Manuel Segade explica que

Hacia 1860, se sofistica el mercado sexual parisino. [...] los clientes pretenden calcar sobre sus relaciones con prostitutas el modelo del amor conyugal. En las casas de citas del Fin de Siglo el cliente imagina poseer a mujeres de categoría muy superior a la suya: se trata de la satisfacción comercial de un deseo imposeíble, una sexualidad fantasmal [...] en espacios creados para el simulacro de la seducción (2008, p.75).

Lo inalcanzable de la satisfacción de ese deseo "imposeíble” es representado en el filme de la mano de los comentarios y caprichos de los clientes que ejemplificaremos en los siguientes párrafos. "El modelo cosmológico del Fin de Siglo obtiene otra de sus credenciales: mundo como texto, mundo como libro, mundo como representación; es decir, mundo representado, mundo escenificado" (Segade, 2008, p.195); y los hombres que acuden a L'Apollonide no pagan simplemente por un intercambio sexual. Imbuidos del pesimismo mencionado más arriba, aquello que compran son los intentos de materializar fantasías y viajes íntimos que envuelven el acto sexual de una parafernalia que trasciende lo físico y, sobre todo, les aleja de la realidad material que les disgusta. El teórico y esteta Theóphile Gautier, primero en aceptar la concepción de la decadencia como estilo estético en sí mismo, defendería que lo verdaderamente bello es lo que no sirve para nada, mientras que lo útil, lo que recuerda a la necesidad degradante de la naturaleza humana, es feo ${ }^{6}$. Contrariamente al naturalismo, el decadentismo propugna el arte por el arte, celebra la búsqueda de lo bello en la artificialidad, el hedonismo y los vicios que la hipocresía moral censura. A contrapelo, de J.K. Huysmans (1884), suele considerarse el manifiesto decadentista por excelencia, siendo también $E l$ retrato de Dorian Gray de Oscar Wlide (1890) una lucidísima puesta en escena del comportamiento y los ideales decadentes, asociados siempre a la clase alta.

Lo insaciable de ese deseo incierto resuena, en L'Apollonide, en la línea de guion del artista que, como hechizado en búsqueda de una modelo perfecta, se asoma fascinado a la entrepierna de Clotilde y Pauline, repitiendo varias veces

\footnotetext{
6 En este contexto escribe su conocida máxima que recuerda que el lugar más útil de una casa son las letrinas, en el prólogo de su novela Mademoiselle de Maupin (1835).
} 
que los hombres no miran nunca suficientemente el sexo de las mujeres. La escalaridad del filme evita los planos cerrados sobre parcelas concretas de sus cuerpos. Se mantiene a una distancia prudente que las preserva de un intrusismo agobiante para dar lugar a primeros planos de sus rostros $\mathrm{u}$ otros más abiertos (medios, americanos, generales cortos) en los que emerge la sensibilidad pictórica que aquí analizamos. Sin embargo, la fijación del cliente pintor en el pubis femenino alude, sin mostrar ningún encuadre que visualmente lo retome, al lienzo naturalista de Courbet El origen del mundo (1866), “probablemente el lienzo erótico más famoso $-\mathrm{y}$ todavía más impactante - del arte moderno [...] el primer plano de un sexo femenino que Courbet ejecuta con soberbia técnica pictórica desmantela cientos de años de fingimiento” (Mínguez \& Rodríguez Moya, 2014: 15).

Siguiendo con el amor por lo artificial, otro de los clientes pide a Léa (Adèle Haenel) que se transforme en una muñeca de porcelana, de articulaciones limitadas, con un vestido vaporoso y blanco sujeto a la cintura por una cinta, el pelo suelto salvo por algún lazo, destacando maquillada de blanco sobre la oscuridad de la habitación. Lo robótico e inerte de su movimiento supera la idea de Galatea, de una creación perfecta, para aproximarse a la búsqueda del erotismo tras los cuerpos femeninos artificiales que Pilar Pedraza aunaba bajo la categoría de Máquinas de amar (1998). A diferencia de la exploración trágica de intentar reconstruir al ser amado de títulos como No es bueno que el hombre esté solo (Pedro Olea, 1973) o La habitación verde (La chambre verte, François Truffaut, 1978), no hay en L'Apollonide duelo alguno que sanar. Más bien al contrario, se trata de aplacar la condición de ser vivo de Léa para convertirla en un objeto decorativo al que no solamente se pueda contemplar sino también poseer sexualmente - un filme reciente que lleva a cabo una exploración similar desde la ciencia ficción contemporánea es Ex Machina (Alex Garland, 2014)-

Un ejemplo más de la querencia por lo artificioso es la apariencia de geisha que el pintor encarga a Pauline, a la cual le pide que le hable en japonés, aunque sea inventado. El japonesismo, moda instaurada a partir de la segunda mitad de siglo y presente en conocidas composiciones de pintores de diferentes sensibilidades (de Manet a Renoir pasando por Tissot o Whistler), queda 
también representado como parte del anhelo por lo exótico, por la exquisitez elegante asociada a cierto secretismo oriental que inspira coloristas kimonos y agujas para el cabello pero también espejos, biombos o depurados arreglos florales que aparecen representados en el filme como parte de la decoración de la casa.

Todo ello da cuenta de que "El erotismo Fin de Siglo es consciente de la importancia del retardo, de que la excitación avance como una carrera de obstáculos [...] la atención se dispersa por el cuerpo femenino como la contemplación de un mosaico, cuyos dorados excitan la mirada hasta el punto donde el deseo desarrolla un tacto imaginario" (Segade, 2008, p.80). Esto no obstante, la estilización de los preparativos para la actividad sexual propiamente dicha no elimina en L'Apollonide lo descarnado del comercio sexual, que en ninguno de los casos se plantea como una relación de seducción entre iguales sino como una rutina que les resulta aborrecible y repugnante y a la que se ven abocadas las chicas huyendo, en algunos casos, de las malas condiciones de otros trabajos como costurera o lavandera. Planos de sus rostros inexpresivos mientras están con clientes o la atención al antes y el después de sus citas funcionan en este sentido.

Además, como una guillotina suspendida en el aire, en esos "después" en que las chicas coinciden para asearse, recomponerse y evitar embarazos no deseados, invade el ambiente la amenaza más temida de todas: contraer una enfermedad venérea cuyas consecuencias empiezan por la pérdida del sustento y terminan con la muerte. En la puesta en escena no hay rastro del enaltecimiento de la debilidad y muerte femeninas, valoradas por la sensibilidad romántica hasta el punto de que Edgar Allan Poe escribía, en 1846, que la muerte de una mujer hermosa es, sin duda, el tema más poético del mundo ${ }^{7}$. La sífilis ataca finalmente a Julie (Jasmine Trinca) y en su empeoramiento y velatorio final, dispuesto con una profusa iluminación blanca, no hay rastro del lirismo mediante el que son representadas (Bronfen, 1992), sobre todo a partir de la Ofelia de Millais (1852) decenas de Atalas, Albines, Damas de Shallott, y en definitiva bellas durmientes que representan a la

\footnotetext{
7 En 'Philosophy of Composition', publicada originalmente en Graham's Magazine (abril de 1846).
} 
"sublime tísica [...] dulce dispéptica, un poco demasiado espiritual para este mundo y un poco demasiado material para el próximo y que, por ello, siempre parece flotando entre ambos" (Dijkstra, 1994, p.29). Pilar Pedraza explica que

las representaciones de la muerte en el arte son tan agradables porque ocurren en un terreno imaginario, ficcional, y porque el placer proviene de la confrontación con la muerte [...] de ese Otro radical que es la Mujer en nuestra cultura. Representar el cadáver bello, joven, femenino o materno es una manera de desactivar su virulencia. Y también, añadimos, de acentuarla, ya que la belleza y la ternura incrementan en el contemplador el deseo sádico de la destrucción o la fusión (2009, p.48).

Contrariamente a tal planteamiento decimonónico, la mirada comprometida de Bertrand Bonello para con las jóvenes prostitutas renuncia a la representación como muerte-sueño para aproximarse — primerísimo primer plano mediantea lo material de las costras y llagas que le salen a Julie en el rostro. La imagen frecuente de las mujeres mirándose al espejo cuando se acicalan, se lavan o buscan arrugas se carga de angustia cuando, tras ser diagnosticada, Julie se observa las marcas en el rostro. Un zoom in se le aproxima mientras la voz over de Maurice, cliente que parece apreciarla, lee una carta que ella no llega a recibir, en la que le dice que la sigue queriendo pero no puede arriesgarse a infectarse, y por ello su relación debe cambiar. Temblorosa y descompuesta, también frente a un espejo intenta arreglarse la noche después de saberse enferma. La imagen de lo que en un primer instante es temor a la vejez, a no servir para la profesión, se convierte abruptamente en el horror al paso del tiempo ante el reflejo de la muerte certera. Un precedente de reflejo trágico es la primera vez que, tras la elipsis que sitúa el relato en 1900, aparece en escena Madeleine. Lo hace convocada por un espejo, estando físicamente fuera de campo. Dos chicas miran hacia ella, reflejada borrosamente en un espejo oval hasta que el cambio a un plano medio confirma a la luz del día la magnitud de sus cicatrices.

Los espejos asociados a la importancia de las apariencias con la que cargan las chicas es un recurso utilizado como marca enunciativa en numerosos encuadres. Segade advierte que "lo visual adquiere la preponderancia que aún perdura como el avance previo a la solicitación sexual. Ver es aquella actividad 
esencialmente excitante" (2008, p.75). Ciertamente, parte del espectáculo de la casa de tolerancia reside en una suerte de pared de cristal o ventanal desde el que algunos clientes pueden observar cómo las chicas trabajan mientras están con otro, sirviendo además de puesto de vigilancia a madame Marie-France. Más adelante veremos cómo el filme subvierte esa relación de poder entre sujeto observador y objeto de la observación. Mencionaremos, como uno de los planos-contraplanos más discursivamente significativos del filme, una puesta en escena con espejo. Madame llama a todas las mujeres para presentarlas a un nuevo cliente, Jacques (Xavier Beauvois). En campo aparecen ambos sentados en un sofá. En un gran espejo horizontal colgado sobre sus espaldas se reflejan todas ellas ataviadas para trabajar, formando una suerte de friso. El contraplano, sin embargo, ofrece un plano medio de ellas arrastrado por un travelling que muestra sus rostros maquillados, desganados, cuyos ojos no sonríen. Una composición similar alberga a Clotilde mientras se quita la ropa, multiplicada en los espejos que envuelven la cama en la que le espera su cliente, que sí que permanece dentro de campo. De este modo, son reencuadradas desde la mise en abîme que supone el espejo, habitáculo de las apariencias, de la simulación, del redoble de lo real.

\section{Exposición y conclusiones. La metamorfosis de la pintura convocada desde el encuadre cinematográfico}

Tal y como avanzábamos más arriba, L’Apollonide hace suya la cultura visual tardodecimonónica para adaptarla a la mirada del siglo XXI sensibilizada con el tema de la prostitución sin renunciar, no obstante, a decisiones estilísticas como el esteticismo de las composiciones, la pantalla partida e incluso la integración postmoderna de la música contemporánea. A propósito del decidido uso de esta última, que llega a romper la transparencia enunciativa en uno de los momentos más emotivos del filme, cuando las mujeres danzan lentamente en parejas consolándose del fallecimiento de Julie, escribe Rodríguez Serrano que "empuja a la puesta en escena misma" (2013, p.37). Los tres subepígrafes siguientes desarrollan cómo el lenguaje cinematográfico absorbe las sensibilidades de diferentes movimientos artísticos para devolverlas al 
espectador integradas en los códigos y devenir narrativo que el relato va generando como propios.

\subsection{El decorativismo academicista}

En las paredes de la maison close lucen, en beneficio de la verosimilitud de la puesta en escena y el alto nivel del establecimiento, pues "No es raro [...] que los más elegantes estén decorados con el mayor lujo, con una suntuosidad costosa, [...] con espejos de pared, sillones cómodos, baratijas, elegantes sanitarios, vajilla cara y grandes cuadros eróticos en las paredes, pintados en ocasiones por algún artista de calidad” (Fuchs, 1996: 291). Pinturas académicas cuyos desnudos no resultan provocadores sino que se ofrecen dóciles a la mirada del espectador bajo el amparo de la tradición. Sin ser atendidas por la enunciación en mayor medida que el resto de atrezzo que puebla el profílmico, obras como Las Oréades, de William-Adolphe Bouguereau (1902), La boîte à bïoux de Guillaume Seignac o Water Babies de Sir Edward John Pointer contribuyen discretamente a la ambientación de época.
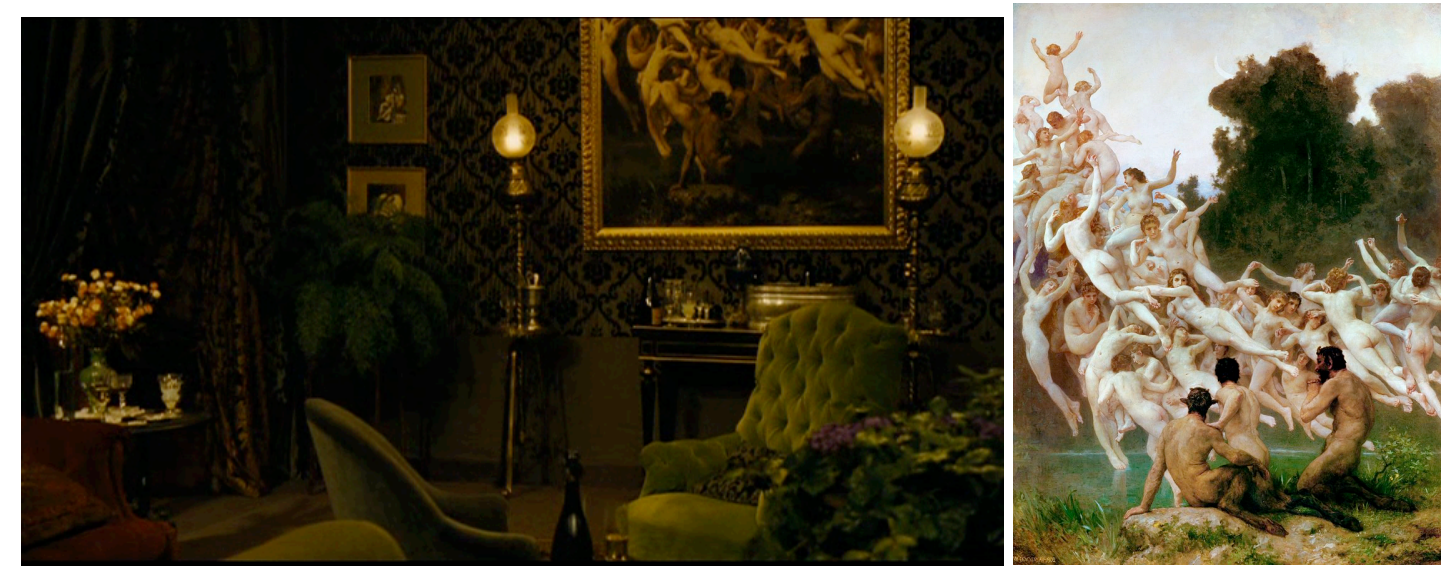

F1. Fotograma del filme (captura propia). F2. Las Oréades, 1902. Lienzo de William-Adolphe Bouguereau (C) Wikimedia Commons

El cúmulo de cuerpos femeninos, arqueados para la cómoda contemplación del observador, danzan conformando un remolino aéreo de ninfas ante los sátiros que las observan todavía sentados, haciendo amago de levantarse hacia ellas. El obvio juego de identificación entre el sátiro, de espaldas al espectador $-\mathrm{y}$ por tanto continuador de su mirada-, y el potencial cliente del burdel ante el torrente de contorsión y palidez femenina, ante la posibilidad de escoger a cualquiera de ellas de entre la multitud, queda justificado de cara a la moral de 
la época por la adscripción al tema mitológico. Lo mismo sucede con el lienzo de Poynter respecto a la tradición de desnudos femeninos en baños y fuentes. Se trata, en ambos casos, de desnudos inofensivos, ligeramente aniñados que nada tienen que ver con la actitud desafiante de las femme fatale. Una ligera chispa de picardía más despierta, tal vez, la obra de Seignac, en la que una jovencita mira fuera del los límites del encuadre con una media sonrisa mientras se reclina indolentemente sobre una gran cabeza de oso cuyo tamaño y feroz aspecto contrastan con su aparente fragilidad. Distraída, pero con la mirada cargada de sugerencia, roza con la punta de los dedos collares de perlas extendidos fuera del pequeño joyero que da nombre al cuadro. De nuevo, su ubicación en el burdel refuerza lo que de reclamo erótico hubiera en la exposición de la adolescente. Por otro lado, no sobra matizar que otras estampas e ilustraciones de más explícito contenido erótico y (tal vez proporcional) menor tamaño pueblan los pasillos y rincones de la casa.

\subsection{El respiro impresionista}

Prácticamente la única secuencia que se desarrolla al aire libre es la salida al campo en que las chicas y Marie-France acuden a la orilla de un río. La primera obra que viene a la mente al asistir al descanso con el que, despreocupadas y con las ataduras de la ropa aflojadas, se distribuyen por el césped con los manteles y comida a su arededor es el imperecedero Almuerzo sobre la hierba de Manet (1863). Este es solamente uno de los referentes a los que la secuencia puede aludir, reclamando también, por ejemplo, el sol y los exteriores campestres de Monet o las muchachas distraídas de cabellos largos y claros de Renoir.

Al margen de esta única secuencia de descanso cuya ociosidad difiere con mucho del aburrimiento de la espera eterna en el interior del burdel, la estética impresionista no se recupera en toda la diégesis. En consonancia con el jugueteo impresionista fresco e intrascendente, en la salida campestre tiene lugar cierta celebración de la vida al sol, del "instante cualquiera"que sirve de momentánea descompresión de la tensión acumulada en el burdel y cuya intención no tiende a buscar la belleza eterna (Eco, 2004). 



F3. Fotograma del filme (captura propia). F4. Mujer con parasol, 1875. Lienzo de Claude Monet (C) Wikimedia Commons.

\subsection{La humanización de la toilette y la desacralización del burdel}

La humanización con la que Bonello contrarresta lo lujosamente artificioso de las noches en L’Apollonide reside en la representación del día a día de las jóvenes en la casa, bañado por una luz blanca que permite el registro de momentos como la inspección higiénica del doctor que debe certificar si están sanas — visita que las atemoriza por la posibilidad de saberse embarazadas o sifilíticas- . Ni las composiciones que las representan aseándose ni los ratos muertos en el salón común pueden eludir los referentes de las toilettes y burdeles parisinos generadas por Degas y Toulouse-Lautrec.

De la aproximación de Degas a los retratos del aseo femenino en las maisons closes dice Erika Bornay que "mezclan amor y rechazo [...]. Son obras de una gran inmediatez y vivacidad que producen una sensación de «verdad»" (1990, p. 249). Los escorzos poco elegantes de las mujeres al asearse trasladan lo incómodo de una higiene a la que aluden constantes conversaciones en las que las chicas se quejan de que están doloridas, tienen la piel pegajosa o escocida debido al necesario uso de sus desinfectantes y otros potingues. El verismo de las poses robadas, instantáneas, que en Degas hacía descender al ídolo femenino de su pedestal, hacen justicia en L'Apollonide al reverso material, naturalista, del delirio nocturno; reverso que hubiera repugnado a cualquier decadentista decimonónico por indigno de ser considerado arte. En palabras de Hollis Clayson, "Describing the whore as material com-modity, to undercut the general outlines of narcissistic male fictions about prostitution, seemsto have required this" (2003, p. 40). 
Una mirada similar lanza Toulouse-Lautrec, aproximadamente desde 1891, de las prostitutas con las que llegó prácticamente a convivir: visión desapasionada cuyos

personajes son representados de manera sincera, sin ninguna idealización, ni siquiera haciendo un especial énfasis en los aspectos de la sexualidad. Lo que sí domina la atmósfera del cuadro, es un sentimiento de soledad en la impasible espera de las mujeres en medio de un decorado pseudo asirio-babilónico (Bornay, 1990, p. 252).
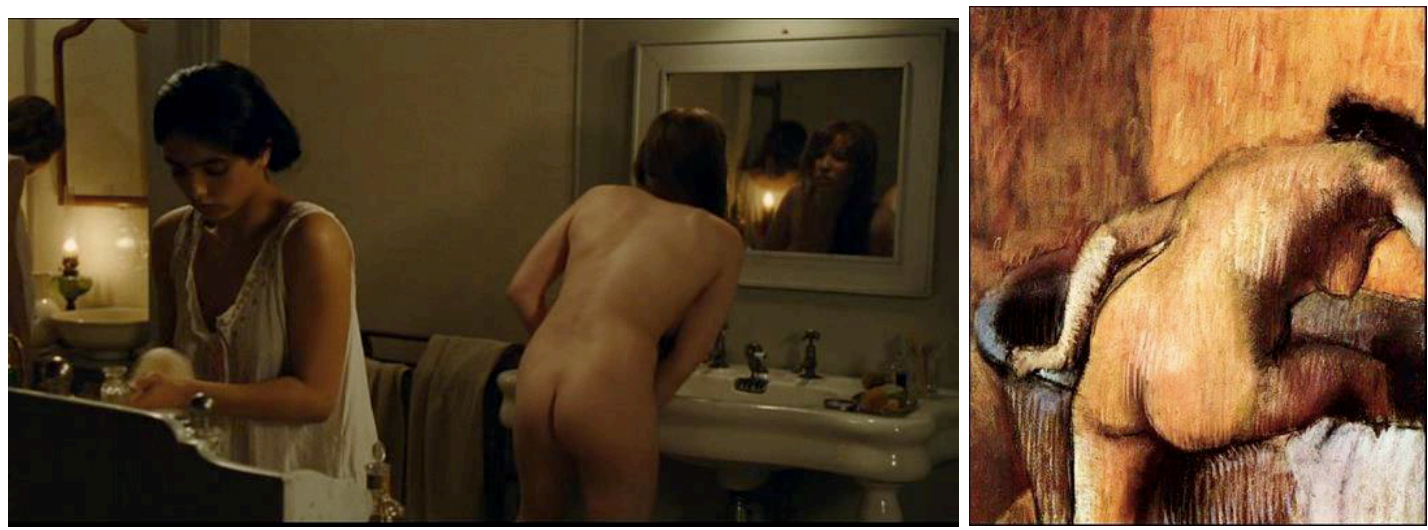

F5. Fotograma del filme (captura propia). F6. El baño de la mañana, 1894. Tolouse-Lautrec (C) Wikimedia Commons


F7. Fotograma del filme utilizado como imagen promocional (captura propia). F8. Salón de la Rue du Molins, 1894. Tolouse-Lautrec (C) Wikimedia Commons

La soledad, la "resignada tristeza" de las prostitutas de Lautrec puede aplicarse tal cual a los encuadres de Bonello. El espacio misterioso que es el burdel de élite de puertas para afuera, como mencionaba Fuchs, revela las miserias de las desdichadas mujeres que lo habitan y da lugar, en ocasiones, a la ternura entre ellas que de nuevo retrata el cineasta recreando abrazos y reposos conjuntos que remiten al pintor. Éste también recurre a la lectura que Samira lleva a cabo 
de un libro que le presta un cliente, en el cual la escritora defiende que las prostitutas tienen el cráneo y el cerebro más pequeño de lo habitual y por ello son criminales de débil inteligencia. El llanto que le provoca la lectura va seguido por corte directo de la degradación de Clotilde, adicta al opio, la cual responde cuando la madame la avisa de que terminará en un burdel peor, infectado, que todas ellas merecen la gonorrea, el castigo. Si bien la última no ha accedido al degradante texto, también en su percepción ha calado el sentir de que “«el sexo de la mujer era el abismo», en su fondo sólo se hallaba Tánatos precedido por el surgimiento y la más terrible y repulsiva de las decrepitudes físicas" (Bornay, 1990, p. 64).

\subsection{La provocación del placer culpable}

El preciosismo enjoyado de las Salomés y Judiths finiseculares emerge, en el filme, en el atuendo que las prostitutas llevan cuando, cada noche, se juntan en el salón a esperar ser requeridas por algún cliente mientras beben, fuman, charlan y se pasean por la estancia. La semidesnudez salpicada de joyas y greñas que envuelven miradas penetrantes y labios rojos, cuyo precedente puede encontrarse en el prerrafaelismo inglés, forma parte de su atavío nocturno. Figuras literarias de la talla de Flaubert, Oscar Wilde y Huysmans ${ }^{8}$ se detienen a recrear con toda precisión sus particulares versiones de la lasciva danza de Salomé, cuyos grados de infantilismo y perfidia varían según cada escritor, si bien a todos es común la capacidad de la adolescente para despertar el deseo del ya viejo Herodes. Así, el atuendo orientalizante propio de las bíblicas cortadoras de cabezas Salomé y Judith, pero también de Dalila, Cleopatra o Circe, inviste a las prostitutas con los lujos perversos con los que la morbosa misoginia finisecular las reescribe y prácticamente eleva a la condición de mito irresistible que conduce a la perdición: collares, diademas enjoyadas en la frente que caen a ambos lados del rostro, brazaletes, cinturones perlados y semidesnudez de cintura para arriba. Aquello que la casa de tolerancia ofrece a los aristócratas y burgueses enriquecidos gracias a la industria textil o papelera es el consumo culpable y a la vez sin consecuencias de esos siempre artificiosos

\footnotetext{
8 En el caso de este último, es una descripción de la pintura de Gustave Moreau, que ficticiamente adquiere Jean Floressas Des Esseintes en A contrapelo.
} 
mitos de su tiempo. La posesión de su Salomé o Cleopatra exenta del riesgo de terminar sin cabeza.

El filme contesta, o actualiza, sin embargo, el mito de la femme fatale desde diversas estrategias. Una de ellas supone el giro final que toman los acontecimientos, y en el que un grupo de ellas vengan, sin mancharse las manos de sangre e inesperadamente, el ataque sufrido por Madeleine. En él asistimos a un baile de máscaras que retrotrae a lo veneciano como último lujo, incluso a lo dieciochesco de alguna peluca empolvada que remite sin remedio a la despedida final de un modo de vida. Clientes y muchachas se esconden tras máscaras emplumadas y brillantes y practican por última vez en el espacio que ha acogido el retrato coral que es L'Apollonide juegos infantiloides similares a los vistos otras veladas, como beber del revés. Uno de los clientes, antiguo amigo de madame, reflexiona sobre lo horrible que encontró la apertura del metro y el desprecio sentido hacia la satisfacción de la gente que sonreía ante la inauguración del medio de transporte urbano por excelencia. Se trata de una última muestra del rechazo decadentista al progreso, a la fealdad de la tecnología contemporánea, al apuro por la utilidad de las cosas. Mientras caminaba por la superficie de París, le dice, pensó en ella y se preguntó qué harían cuando la casa cerrara. Marie-France le responde, con su sonriente serenidad, que el resto de casas también cerrarán. Él le pide, mientras la cámara atiende las caricias, los juegos y el divertimento todavía sosegado del resto de jóvenes, que siga siendo ella, y matiza: que aún sin L’Apollonide mantenga las flores, la música, los vestidos lujosos, el color, el champán. La última plegaria del decadentista insiste en el mantenimiento de lo decorativo, lo artificial entendido como esencia.

Mientras tanto, las mujeres seducen y fingen dejarse seducir por los clientes enmascarados, acompañadas por una bellísima compañera negra que ha merodeado a sus anchas por la casa durante parte del filme. De nuevo muestra del exceso exótico y del gusto por el peligro elegante, algunas noches acude al burdel una pantera a la que, significativamente, un cliente apoda Vuitton9. La

9 El nombre de la pantera alude a Louis Vuitton (1821-1892), fundador de la homónima empresa dedicada a la moda y complementos de lujo, que llegó a trabajar personalmente al servicio de la emperatriz Eugenia de Montijo. No se trata de la única referencia al diseño y la 
fiera parece ser un elemento decorativo más que replicar los animales representados en los lienzos académicos colgados en las paredes y refuerza la extravagancia e impasibilidad de quienes todo lo pueden comprar. Sin embargo, tiene un papel central en el clímax que abrocha el relato. Es este el punto en que el relato invierte la posición de objeto observado que han tenido hasta el momento las prostitutas.

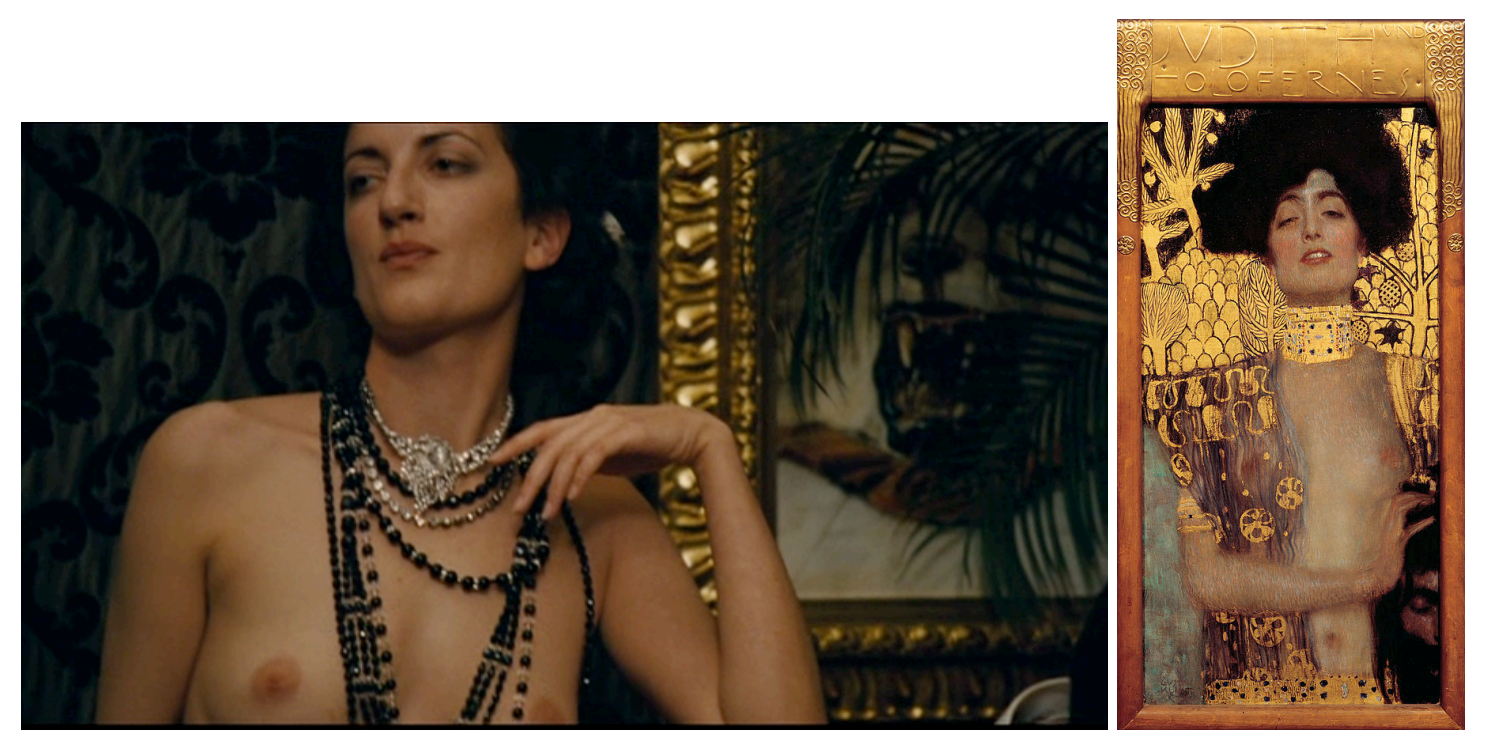

F9. Fotograma del filme (capturas propias). F10. Judith I, 1901. Gustav Klimt, (C) Wikimedia

Commons.

Como en tantas otras ocasiones, Samira se lleva de la mano a un cliente enmascarado. El estallido de fuegos artificiales que conmemoran el Día de la Bastilla distraen a algunas de las chicas que corren a observarlos. La celebración del fin del orden aristocrático resuena con el estruendo de los cohetes fuera de campo, que redoblan el ocaso de otra época. La pantera gruñe mientras pasea inquieta por detrás de los divanes y es calmada por las caricias de Léa, que le dice que no se preocupe: es el Día de la Bastilla, pero nadie la va a decapitar. Un dueto de La Bohème de Puccini empieza a sonar mientras un montaje paralelo dispone diversas secuencias que tienen lugar a la vez. Por un lado, enmascarada, Madeleine está teniendo sexo con un cliente por primera vez en la casa desde que su rostro quedó deformado. El clímax operístico coincide con la mostración del techo abovedado de cristal y la escalera que riman con los también a Jeanne Paquin (1869-1936), paradigmática diseñadora francesa cuya moderna visión de la moda —como espectáculo y como negocio — tuvo un fuerte impacto internacional. 
planos que los mostraron cuando resonaban sus gritos habiendo sido atacada. Recorriendo ese mismo espacio, Samira deja a su cliente todavía vestido y con la máscara puesta para ir en busca de champán. A modo de despedida, la enunciación acompaña brevemente a Clotilde, que se acerca a su pintor con una máscara de mariposa, y a madame Marie-France junto al lecho de sus hijos pequeños. El punto de vista regresa al cliente enmascarado de Samira, que se mira en un espejo. La puerta de su habitación se abre y por ella entra la pantera. El hombre, desconcertado, retira su máscara mientras el animal ruge frente a él. Desde el mismo lugar que otros clientes y Marie-France observaban a algunas de las chicas mientras estaban en la habitación con algún hombre, cuatro de ellas miran fijamente, con atención e impertérritas hacia el interior de la estancia. Sus labios están pintados de rojo imitando la sonrisa perpetua de Madeleine, que invade las mejillas con las comisuras sonrientes. El rugir de la pantera connota la muerte o la desfiguración del atacante de "la judía", la consumación de una inesperada venganza final de las chicas en un acto de reivindicación de justicia a cuenta propia que queda implícita, en fuera de campo. Como una recuperación parcial de la concepción de Judith heroica, Samira seduce al otro, al enemigo infiltrado, para desenmascararle y acabar con él desde una posición que en tanto prostituta, como sus compañeras, no pudo ocupar: la de observadora del espectáculo violento.

\subsection{Conclusión. La hora de los monstruos, la hora de las máscaras}

La imagen más pregnante de una de las escenas finales se corresponde con el rostro ya deforme de Madeleine, tras haber tenido sexo en el baile de máscaras. De sus ojos gotean densas lágrimas blancas que se deslizan hasta las cicatrizadas comisuras de sus labios. Ese primer plano cierra un círculo simbólico, pues pone en escena un sueño que ella le relató a su atacante antes de que le pidiera atarla. Algo de lo complejo del simbolismo que prefigura el sentir surrealista se filtra en el relato. De forma casi premonitoria, le explica que soñó que él parecía querer hacerle daño por un momento; que sintió su semen subir hasta sus ojos y caer en forma de lágrimas; que su boca es roja, que no puede parar de llorar; que él le llevaba una esmeralda para salvarla saldando sus deudas. Al cierre de la cinta no hay salvación ni libertad alguna, sino venganza en su nombre. 
El arranque de L'Apollonide marcaba desde la desfiguración de la mujer el desgarro final de la belleza clásica que ya se venía descomponiendo. Un final violento que terminaba de agotarse mientras, en palabras del director,

no hacemos más que asistir a la degradación de las cosas y ver cómo se van estropeando las chicas. Creo que no hay nada más conmovedor que una forma de belleza que se va marchitando lentamente y que jamás volverá a nacer... Una lenta caída de la magnificencia... Una fiesta desesperada. Lo que viven estas mujeres para no derrumbarse ${ }^{10}$

De la conclusión del relato no puede dejar de observarse, sin embargo, la potencia del montaje paralelo que recupera a la judía marcada, que la reintegra —enmascarada - en el comercio sexual. La rareza resulta interesante. Resulta, de hecho, el centro de la teatralizada celebración en que, como coreografiados, diferentes personajes desnudan y acarician, como explorándola. Madeleine asiste a la velada, fuera de L’Apollonide, invitada como atracción especial debido a su particularidad física. De forma excepcional, no va velada de negro sino que su deformidad se ha acentuado mediante un maquillaje que desde la cultura visual del siglo XXI recuerda el de un payaso siniestro, cuando no a la prefiguración de una suerte de Joker. Al son de lo lo dieciochesco de música mozartiana, la "gran marioneta", como la describe una de las mujeres asistentes, ocupa el centro de una clásica, elegante composición que representa el inicio de una orgía en la que participan lo que el siglo XX entenderá como freaks. Un zoom in se acerca delicadamente al rostro inexpresivo, contenido, de la mujer a merced de las aproximaciones de quienes les rodean. Es entonces cuando, rompiendo una de las reglas básicas del cine hegemónico, Madeleine mira a cámara apelando a la posición inevitablemente voyeurística, del espectador, incomodándole con una mirada vidriosa cargada de resistencia que prefigura de forma clara los angustiosos rostros expresionistas que se multiplicarán con la llegada del siglo XX. Lo esperpéntico rompe la cuarta pared, como rompe el raccord el mantenimiento de la actante de Clotilde transcurrida una elipsis de más de cien años. Es uno de los muchos ecos

10 Recuperado de la "Conversación entre Bertrand Bonello y Laure Adler", abril, 2011: https://intermediodvd.wordpress.com/2012/08/24/casa-de-tolerancia-lapollonideconversacion-entre-laure-adler-y-bertrand-bonello-3/ Consultado por última vez el 30 de octubre de 2017. 
visuales que resuenan entre las imágenes y el tratamiento sonoro de L'Apollonide, que parece querer demostrar que "toda obra del pasado está reflejando, al ser analizada o estudiada, preocupaciones del presente [...] que lo contemporáneo no es un dato sino un estilo que atraviesa toda la Literatura y toda la Historia del Arte [...] que atraviesa la fibra de la actualidad en cuanto su relectura lo acerca a nosotros" (Barañano, 2016: 90-91).

\section{Referencias bibliográficas}

Barañano, K. de. (2016). Criterios sobre la historia del arte. Madrid: Kailas.

Bazin, A. (1990). ¿Qué es el cine? (2a ed.). Madrid: Rialp.

Benjamin, W. (2004). Sobre la fotografía. Valencia: Pre-Textos.

Bornay, E. (1990). Las hijas de Lilith. Madrid: Cátedra.

Bronfen, E. (1992). Over her dead body: death, femininity and the aesthetic. Manchester : Manchester University Press.

Clayson, H. (2003). Painted Love. Prostitution in French Art of the Impressionist Era. The Getty Research Institute.

Dijkstra, B. (1994). Idolos de perversidad : La imagen de la mujer en la cultura de fin de siglo. Barcelona: Círculo de Lectores.

Eco, U., De Michel, G., \& Pons Irazazábal, M. (2004). Historia de la belleza. Barcelona: Lumen.

Fuchs, E. (1996). Historia ilustrada de la moral sexual. Madrid: Alianza.

Gaudreault, A. (1988). Du littéraire au filmique: système du récit. Paris: Presses de l'Université Laval.

Gómez Tarín, F. J., \& Marzal Felici, J. J. (2015). Diccionario de conceptos y términos audiovisuales : herramientas para el análisis fílmico. Madrid: Cátedra.

Mínguez Cornelles, V., \& Rodríguez Moya, I. (2014). Visiones de pasión y perversidad. Fernando de Villaverde Ediciones.

Losilla, C. (2012). A la espera del fin. Caimán cuadernos de cine.

Ortega Ventureira, P. (2015). La mujer crucificada en el fin de siglo. Madrid: Universidad Autónoma de Madrid.

Pedraza, P. (1991). La bella, enigma y pesadilla: esfinge, medusa, pantera... Barcelona: Tusquets Editores.

Pedraza, P. (1998). Máquinas de amar: secretos del cuerpo artificial. Madrid: Valdemar.

Pedraza, P. (2009). El regreso de la mujer muerta. Dossiers feministes, 13, 4550. 
Rodríguez Serrano, A. (2013). Más allá del pop: Primeros apuntes sobre la música en Bertrand Bonello. El rayo verde, 31-37.

Segade, M. (2008). Narciso fin de siglo. Barcelona: Editorial Melusina.

Sorolla Romero, T., \& García Catalán, S. (2014). Morfologías de nuestros áridos días felices. L'Atalante. Revista de estudios cinematográficos, 46-52.

Villena, L. A. de (2001). Diccionario esencial del fin de siglo. Madrid: Valdemar. 